\title{
Osteomielitis supuratif kronis pada mandibula edentulus Chronic suppurative osteomyelitis on edentulous mandible
}

\author{
${ }^{1}$ Leliya Syamsoelily, ${ }^{2}$ Surijana Mappangara, ${ }^{2}$ M. Hendra Chandha, ${ }^{2}$ Muhammad Ruslin \\ ${ }^{1}$ Dokter gigi di Makassar \\ ${ }^{2}$ Bagian Bedah Mulut dan Maksilofasial \\ Fakultas Kedokteran Gigi Universitas Hasanuddin \\ Makassar, Indonesia
}

\begin{abstract}
Osteomyelitis is an infection of the jaw that extends to the jaw bone, which is the spongy, bone marrow, cortex, and periosteum. Infection occurs in the calcified bone when fluid in the medullary cavity or under the periosteum interfere with the blood supply. In this case, it was reported an elderly patient with a diagnosis of chronic osteomyelitis of mandible edentulous dextra. The treatment were sequesterectomy and extraction the radix of tooth 43 by general anesthesia, and combinating with antibiotics. It was concluded that patient of chronic suppurative osteomyelitis of the mandible edentulus could be diagnosed through clinical and radiological examination, and successfully treated with sequesterectomy and extracting the radix under general anesthesia. So the improvement of systemic condition, food nutrition, vitamin therapy, accelerate the healing process. Treatment of focal infection as soon as possible to avoid more severe complications.
\end{abstract}

Key word: chronic osteomyelitis, mandible, edentulous

\begin{abstract}
ABSTRAK
Osteomielitis rahang adalah suatu infeksi yang meluas pada tulang rahang, yang mengenai spongiosa, sumsum tulang, korteks, dan periosteum. Infeksi terjadi pada bagian tulang yang terkalsifikasi ketika cairan dalam rongga medula atau di bawah periosteum mengganggu suplai darah. Dalam kasus ini dilaporkan seorang pasien yang berusia lanjut dengan diagnosis osteomielitis kronis pada mandibula edentulus kanan. Penanganan yang dilakukan adalah sekuesterektomi dan pencabutan sisa akar gigi 43 dalam kondisi anastesi umum, dan dikombinasi dengan pemberian antibiotik. Disimpulkan bahwa penderita osteomielitis supuratif kronis pada mandibula edentulus dapat didiagnosis melalui pemeriksaan klinis dan radiologi, dan sukses dirawat dengan pilihan perawatan sekuesterektomi, dan pencabutan sisa akar di bawah keadaan anastesi umum. Jadi perbaikan keadaan umum, nutrisi makanan, terapi vitamin, mempercepat proses kesembuhan. Penanganan fokal infeksi sesegera mungkin menghindari komplikasi yang lebih berat.
\end{abstract}

Kata kunci: osteomielitis kronis, mandibula, edentulus

Koresponden: Leliya Syamsoelily, Jl. Sultan Babulah sk 10/42, Ambon. E-mail: leliya/syamsoelily@gmail.com

\section{PENDAHULUAN}

Osteomielitis rahang adalah suatu infeksi yang sifatnya ekstensif pada tulang rahang, yang mengenai spongiosa, sumsum tulang, korteks,dan periosteum. Infeksi terjadi padabagian tulang yang terkalsifikasi ketika cairan dalam rongga medula atau di bawah periosteum mengganggu suplai darah. Tulang yang terinfeksi menjadi nekrosis ketika terjadi iskemia. Perubahan pertahanan host yang mendasar terdapat pada mayoritas pasien yang mengalami ostemielitis pada rahang. Kondisi-kondisi yang mempengaruhi persarafan tulang menjadikan pasien rentan terhadap berlangsungnya ostemielitis.Kondisi tersebut, antara lain sinar radiasi,osteoporosis,osteopetrosis,penyakit tulang Paget, dan tumor ganas tulang. ${ }^{1}$

Penatalaksanaan osteomielitis supuratif kronis pada mandibula edentulus membutuhkan kerja sama yang intensif dengan bagian medis lainnya. Selain itu, tingkat keberhasilan perawatan juga ditentukan oleh kondisi sistemik penderita secara umum.Berikut ini dilaporkan penatalaksanaan kasus osteomielitis supuratif kronis yang terjadi pada mandibula yang edentulus.

\section{KASUS}

Pasien laki-laki yang berusia 60 tahun, datang ke RS Hikmah, Makassar dengan keluhan sering keluar darah pada dagu sebelah kanan yang disertai nanah dan sudah berlangsung selama 1 tahun.Tidak ada keluhan rasa nyeri pada daerah tersebut.Keadaan umum pasien, antara lain demam (-), alergi (-), rinitis (-), asma (-), batuk (-), riwayat pembedahan sebelumnya $(-)$, merokok $(+)$, edentulus rahang atas dan rahang bawah $(+)$.

Keadaan umum lainnya dari pasien baik dengan kesadaran kompos mentis, tekanan darah 140/80 mmHg,nadi 68x/menit,pernapasan 16x/menit,teratur, dengan suhu afebris.

Pada pemeriksaan fisis, pada daerah ekstraoral terdapat fistula dan pus yang keluar pada daerah dagu kanan (gambar 1A,B).Sedangkan pada pemeriksaan intraoral tampak adanya edentulus pada daerah 
mandibula dan sisa akar gigi 43 , serta terdapat pus jika dilakukan penekanan.

\section{Pemeriksaan radiografi}

Pemeriksaan radiologi meliputi foto panoramik, menampakkan gambaran destruksi korteks dan medula mandibula kanan dan tampak fistula akar gigi 43 (gambar 2).

Berdasarkan pemeriksaan klinisdan radiografis, kasus ini didiagnosis sebagai osteomielitis supuratif kronis pada regio kanan mandibula yang edentulus. Rencana perawatan yang akan dilakukan adalah sekuesterektomi,pencabutan sisa akar gigi 43 dalam anastesi umum yang dikombinasi dengan pemberian antibiotika. Skrining pasien sebelum pembedahan adalah pemeriksaan di laboratorium, meliputi darah lengkap, foto toraks, penjangkaran dan uji fisiologi paru.

\section{PENATALAKSANAAN}

Persiapan alat, bahan operasi, pasien, operator, dan asisten telah dilakukan sebelum operasi dimulai.

Tahapan operasi yang dilakukan meliputi asepsis dan antiseptik, kemudian disinfeksi area ekstraoral dan area intraoral (gambar 3).Selanjutnya, dilakukan injeksi vasokontriktor daerah ekstraoral dan intraoral, kemudian insisi tajam dengan blade no. 15 pada intraoral dan ekstraoral,disusul eksplorasi daerah 43 dan pencabutan sisa akar gigi 43. Sekuesterektomi dilakukan dengan burtulang dan kuretase pada soket gigi 43 yang diekplorasi pada daerah intraoral dan ekstraoral.Setelah itu,dilakukan pembersihan daerah fibrosis dengan diseksi tajam dan penanganan pendarahan dengan kauter, disusul pembersihan daerah operasi menggunakan gentamycine injeksi yang dilarutkan dalam $200 \mathrm{cc} \mathrm{NaCl} \mathrm{0,9 \% .} \mathrm{Terakhir,}$ dilakukan penjahitan luka operasi pada daerah intraoral dan ekstraoral.

Pada hari kedua pascaoperasi, keadaan umum kompos mentis,kembung (+),pendarahan(-).Medikasi berupa cefotaxine $2 \times 1 \mathrm{~g} I V$, ranitidine $2 \times 1 \mathrm{amp} \mathrm{IV}$, novalgin $2 \times 1 \mathrm{amp} \mathrm{IV}$, metrodinazole $3 \times 500 \mathrm{mg}$ IV dilanjutkan, dan dilakukan penggantian verban. Pasien tetap diminta berkumur tiap selesai makan.

Pada hari ketiga pascaoperasi, keadaan umum kompos mentis.Medikasi,infus,dan diet dilanjutkan. Selanjutnya, follow up hari keempat pascaoperasi mendapatkan keadaan umum pasien baik sehingga diputuskan rawat jalan dan obat dilanjutkan dengan obat peroral.
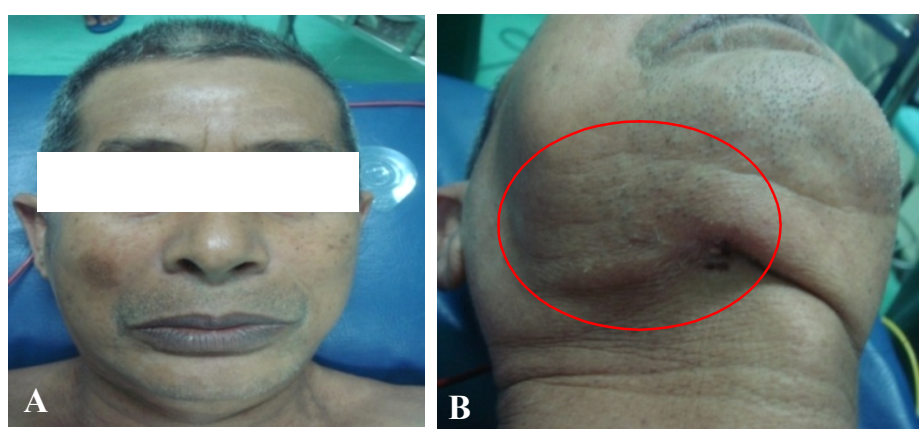

Gambar 1A Tampak depan, B daerah ekstraoral tampak fistel dan pus

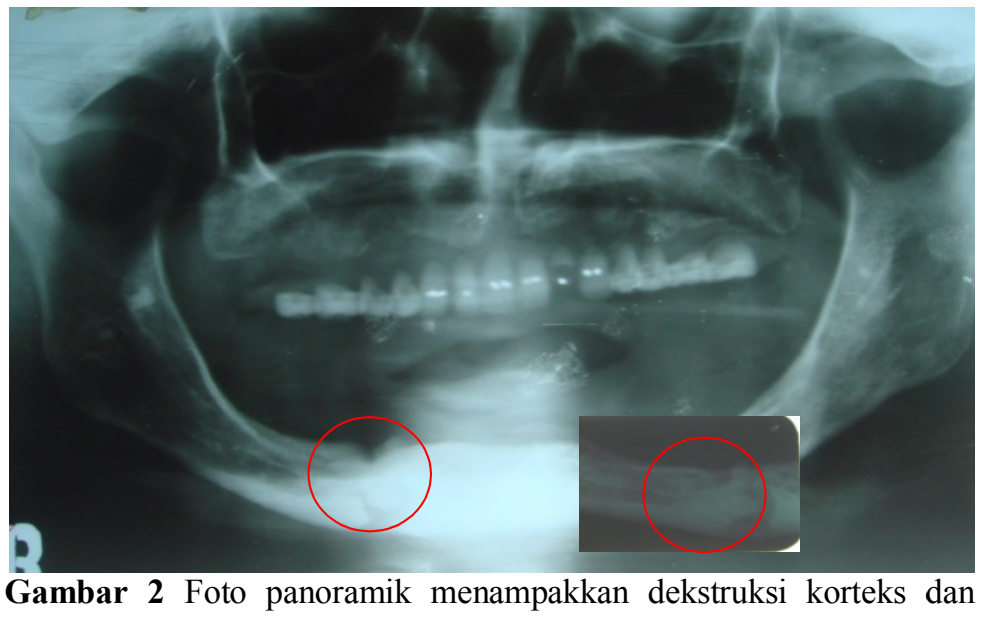
medula mandibula kanan dan fistel akar gigi 43 

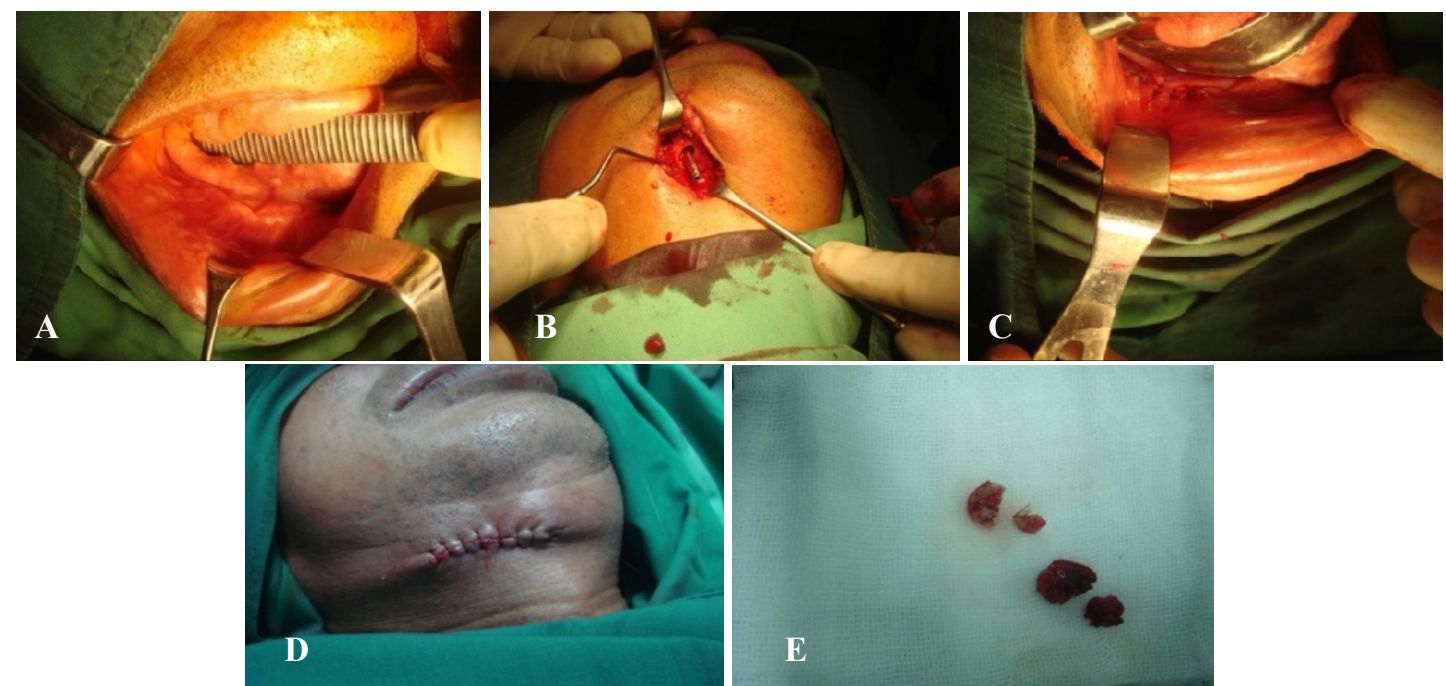

Gambar 3A Tampak klinis intraoral, B setelah operasi tampak daerah dekstruksi tulang tembus dari intraoral ke ekstraoral, C tampakan intraoral setelah dilakukan penjahitan, D tampakan ekstraoral setelah dilakukan penjahitan, $\mathbf{E}$ sisa akar gigi berisi fibrosis.

\section{PEMBAHASAN}

Osteomielitis dental atau disebut osteomielitis pada tulang rahang adalah keadaan infeksi akut atau kronis padatulang rahang, yangbiasanya disebabkan olehbakteri,yang menyebabkan dekstruksi tulang. ${ }^{2,3}$ Sumber lain mendefinisikan osteomielitis sebagai suatu inflamasi tulang dan sum-sum tulang, yang berkembang setelah infeksi kronis.Osteomielitis dapat diklasifikasikan menjadi akut, subakut, atau kronik tergantung pada gambaran klinisnya. ${ }^{6}$ Gejala-gejala fisik pada penderita yang tidak dapat didiagnosis sebagai penyakit khusus,seperti kelelahan,dan nyeri pada sendi atau edema pada jaringan di sekitar tulang rahang sering terjadi karena adanya infeksi bakteri yang tersembunyi pada tulang rahang yang menyebarkan toksin ke jaringan sekitarnya. ${ }^{2}$

Osteomielitis menurut Bernier, dkk., dibedakan atas suppurative osteomyelitis, non-suppurative osteomyelitis, dan osteoradionecrosis. Suppurative osteomyelitis dibedakan menjadi acute suppurative osteomyelitis dan chronic suppurative osteomyelitis. Sementara non-suppurative osteomyelitis dibedakan atas chronic focal sclerosing osteomyelitis, chronic diffuse sclerosing osteomyelitis, dan Garre's chronic sclerosing osteomyelitis. ${ }^{5}$

\section{Patogenesis, tanda dan gejala klinik}

Osteomielitis pada tulang rahang bermula dari infeksi dari tempat lain yang masuk ke dalam tulang dan membentuk inflamasi supuratif pada medula tulang, karena tekanan dari pus yang besar. Infeksi kemudian meluas ke tulang spongiosa menuju ke daerahkorteks tulang,sehingga struktur tulang rahang yang harusnya kompak dan padat menjadi rapuh dan berlubang-lubang seperti halnya sarang lebah dan mengeluarkan pus yang bermuara dikulit sepertifistel yang tampak seperti bisul. Jika kondisi demikian dibiarkan, akibatnya bisa fatal karena pada rahang yang rapuh dapat mengalami fraktur patologis. ${ }^{2}$ Osteomielitis lebih sering terjadi pada mandibula daripada maksila; dan pada keadaan akut sifatnya simtomatik, sedangkan pada keadaan kronikbiasanya asimtomatik tetapi juga disertai eksaserbasi secara episodik. Penyakit ini jarang terjadi pada maksila karena maksila adalah tulang kortikal yang tipis dan kaya akan suplai darah. ${ }^{9}$ Gejalanya berupa rasa nyeri dan pembengkakan yang sifatnya bervariasi,adanya limpadenopati regional, rasa panas dan malaise, gigi goyang dan sensitif terhadap perkusi, adanya fistel, paraestesia n.mentale pada bibir bawah,trismus jika otot mastikasi terinfiltrasi, pembesaran mandibula, dan rahang asimetris. ${ }^{3}$ Gejala awalnya seperti nyeri gigi dan terjadi pembengkakan di sekitar pipi, kemudian pembengkakan ini mereda. Selanjutnya penyakitnya bersifat kronis membentuk fistel dan kadang tidakmenimbulkan rasa nyeripada penderita. ${ }^{2}$

Pada sebagian besar kasus, tidak ada rasa nyeri pada daerah wajah, tetapi ada keengganan pihak medis untuk mencabut gigi yang gangren, serta kebiasaan pasien yang sering menunda pengobatan giginya yang infeksi. Kesulitan terapi osteomielitis adalah minimnya aliran darah yang menuju daerah infeksi pada rahang tersebut, sehingga mencegah antibiotik mencapai sasarannya. ${ }^{2}$

\section{Etiologi}

Penyebab utama yang paling sering dari osteomielitis adalah penyakit periodontal, seperti 
gingivitis,pyorrhea, atau periodontitis. Bakteri yang berperan terhadap proses terjadinya penyakit ini yang tersering adalah Staphylococcus aureus. Kuman yang lain adalah Streptococcus, Pneumococcus, Klebsiela spp, Bacteroides spp, dan bakteri anaerob lainnya. ${ }^{4}$ Lewat penyakit periodontal, juga dapat menyebabkan penyakit jantung melalui perjalanan infeksinya. Kekurangan vitamin $\mathrm{C}$ dan bioflavanoid dapat menyebabkan sariawan yang merupakan salah satu awal penyakit periodontal, dapat dicegah dengan mengkonsumsinya secara cukup.

Penyebab lain osteomielitis adalah tertinggalnya bakteri di dalam tulang rahang setelah pencabutan gigi. Hal ini terjadi karena buruknya daerah operasi pada daerah gigi yang diekstraksi dan tertinggalnya bakteri di dalamnya. Hal tersebut menyebabkan tulang rahang membentuk tulang baru di atas soket sebagai pengganti pembentukan tulang baru di dalam lubang, yang meninggalkan ruang kosong atau kavitas pada tulang rahang. Pada kavitas ini ditemukan jaringan iskemik akibat berkurangnya vaskularisasi, nekrotik, osteomielitik, gangren dan bahkan sangat toksik.Kavitas tersebut akan bertahan, memproduksi toksin dan menghancurkan tulang di sekitarnya, dan membuat toksin tertimbun dalam sistem imun. Bila sudah sampai keadaan seperti ini, makapenanganannyaharus ditanganioleh ahli bedah mulut.

Penyebab umum yang ketiga dari osteomielitis dental adalah adanya gangren radiks. Tidak tuntasnya pencabutan gigi sehingga masih ada sisa akar yang tertinggal di dalam tulang rahang, selanjutnya akan memproduksi toksin yang akan merusak tulang di sekitarnya sampai gigi dan tulang nekrotik di sekitar hilang. Bukti lain menyebutkan bahwa osteomielitis dengan gejala adanya inflamasi akibat penggunaan antibiotik untuk kemoterapi secara intens mengalami peningkatan. ${ }^{7}$ Diagnosis histopatologis osteomielitis diperoleh dari suatu osteomielitis yang terinflamasi kronis aktif dan resobsi tulang yang dikultur. ${ }^{8}$

Pada pembedahan gigi, trauma wajah yang melibatkan gigi, penggunaan kawat gigi, atau pemasangan gigitiruan jembatan akan menyebabkan tekanan pada gigi atau menarik gigi dari soketnya, dapat menjadi awal osteomielitis.

Selain penyebab osteomielitis di atas, infeksi berikutjuga bisa disebabkanoleh trauma berupa patah tulang yang terbuka, penyebaran dari stomatitis, tonsilitis, infeksi sinus, furunkolosis maupun infeksi hematogen. Inflamasi yang disebabkan oleh bakteri piogenik ini meliputi semua struktur pembentuk tulang, mulai dari medula, korteks dan periosteum, dan semakin parah pada keadaan penderita dengan daya tahan tubuh rendah. ${ }^{2}$

\section{Terapi}

Penderita osteomielitis sebaiknya dirawatinap di rumah sakit. Penanganan osteomielitis adalah menghilangkan faktor penyebabnya,yaitu gigi yang terinfeksi segera diekstraksi, bila ada sekuester tulang matinya dibuang dengan sekuesterektomi, serta pemberian antibiotik secara adekuat. Dengan kata lain, kombinasi dari insisi, drainase, ekstraksi gigi, dan sekuesterektomi, dan perawatan secara medikamentosa dengan antibiotik. Antibiotik yang diberikan, yaitu secara intravena dalam dosis tinggi selama 3-4 hari. Penanganan selanjutnya dapat dilanjutkan secara peroral selama 2-4 minggu, tergantung dari keparahan penyakit, penyebabnya, dan respon klinisnya. Antibiotik pilihan yang dapat diberikan adalah penicillin $3 \times 10^{6}$ unit $/ 4$ jam iv; jika alergi terhadap penicillin, dapat diganti dengan clindamycin $\left(600 \mathrm{mg} / 6 \mathrm{jam}\right.$ iv) ${ }^{4}{ }^{4}$

Prosedurinimembutuhkan tindakan operasiagar terbentuk penulangan baru yang sehat. Perbaikan keadaan umum, nutrisi, terapi vitamin, membantu mempercepat proses penyembuhan.

Lewat penatalaksanaan kasus ini, disimpulkan bahwa osteomielitis supuratif kronis pada mandibula edentulus didiagnosis melalui pemeriksaan klinis dan radiologi, dan sukses dirawat dengan pilihan perawatan sekuesterektomi,dan pencabutan sisa akar di bawah keadaan teranastesi umum. Penanganan fokal infeksi secara sesegera mungkin, dapat menghindari terjadinya komplikasi-komplikasi yang lebih berat.

\section{DAFTAR PUSTAKA}

1. Cilmiaty R. Infeksi odontogen. Available from: URL http://www.dentalword.com. Accessed on Jan 20, 2010.

2. Osteomielitis rahang. Available from: URL http://www.duniakedokterandokterkecil.com. Accessed on Jan $20,2010$.

3. Larheim TA, Westesson PL. Maxillofacial imaging. Germany: Springer; 2006. p. 119.

4. Frasgiskos DF. Oral surgery. Berlin: Springer; 2007. p. 360.

5. Baltensperger M, Gerold E. Osteomyelitis of the jaw definition and classification. Available from: URL http.www. springer.com. Accessed on Jan, 2010.

6. Yeoh SC, Maemahon S, Schifter M. Chronic suppurative osteomyelitis of mandible: case report. Aus Dent J 2005; 50 (3): 200.

7. Sato T, Shigwaki S, Kazunori K, Akito T, Takenori N. Chronic osteomyelitis of the mandible. Tokyo: Department of Dental Radiology. 
8. Guzerdemir E, Hilal UT, Can B, Nebil B. Mandibular osteomyelitis due to a failed root kanal treatment in a patient with multiple myeloma. Gulhane TD; 2007; 49: 266.

9. Conor PB, David CR, Leo FA. Osteomyelitis of the maxilla secondary to osteoporosis: A case report of 2 cases in sisters. J Oral Maxillofac Surg 2007: 144. 